\title{
INCREASING ELEMENTARY SCHOOL EDUCATION QUALITY THROUGH COMMITTEE SCHOOL PARTICIPATION APPROACH
}

\author{
Lukman Hakim \\ Universitas Islam Negeri Mataram, Nusa Tenggara Barat, Indonesia \\ Email: lukmanhakimvictor@gmail.com
}

DOI: 10.35445/alishlah.v12.i2.215

Accepted: August $5^{\text {th }}, 2020$. Approved: December $21^{\text {st }}, 2020$

Published: December 30 ${ }^{\text {th }}, 2020$

\begin{abstract}
The aim of study was to find out the approach of to develop of community participation in improving the quality of education process. Community had the important role in education because the community gave the impact on education quality progress. The research used descriptive qualitative approach. Data collection techniques consisted of observation, interviews, and documentation. Data analysis was carried out in two stages, namely (1) data analysis in single or individual cases and (2) cross-case data analysis. The results of the study concluded that the approach of community participation in the implementation of elementary school education programs in Mataram is the school as a community center. The implication of the results is the concept of developing the community in the process of elementary school education in Mataram and increasing awareness of all parties in formulating the concept of education process.
\end{abstract}

Keywords: School Committee, Education, Primary School

\section{PENINGKATAN KUALITAS PENDIDIKAN SEKOLAH DASAR MELALUI PENDEKATAN PARTISIPASI KOMITE SEKOLAH}

\begin{abstract}
Abstrak
Tujuan penelitian ini adalah untuk mendapatkan pendekatan partisipasi komite sekolah dalam meningkatkan kualitas pendidikan sekolah dasar di Kota Mataram. Komite sekolah memiliki peran penting dalam penyelenggaraan pendidikan dikarenakan bisa menjadi bagian kontrol dalam manajemen penyelenggaraan pendidikan di sekolah. Penelitian ini menggunakan pendekatan penelitian kualitatif deskriptif. Teknik pengumpulan data yang digunakan dalam penelitian ini terdiri dari observasi, wawancara, dan dokumentasi. Teknik analisis data terdiri dari tiga tahap yaitu reduksi data, display data, dan penarikan simpulan. Hasil penelitian menyimpulkan bahwa pendekatan partisipasi komite sekolah berperan sebagai pusat komunitas di lingkungan sekolah untuk meningkatkan kualitas pendidikan sekolah dasar di Kota Mataram. Implikasi hasil penelitian
\end{abstract}


Al-Ishlah: Jurnal Pendidikan - ISSN: 2087-949o (p); 2597-940X (e)

Vol. 12, No. 2 (2020)

menunjukkan bahwa keberadaan komite sekolah harus dikembangkan agar bisa memberikan peran yang maksimal dalam pengawasan penyelenggaraan pendidikan sekolah dasar. Masyarakat memiliki kesadaran untuk berpartisipasi dalam merumuskan konsep penyelenggaraan pendidikan.

Kata Kunci: Komite Sekolah, Pendidikan, Sekolah Dasar

\section{PENDAHULUAN}

Keberadaan komunitas sekolah yang tertuang dalam wadah komite sekolah untuk penyelenggaraan proses pendidikan pada tingkat Sekolah Dasar (SD) memiliki peran yang sangat penting. Keberhasilan penyelenggaraan program pendidikan di sekolah dasar dipengaruhi oleh peran semua pihak. Artinya bukan hanya warga sekolah seperti siswa, guru, dan kepala sekolah. Namun, orang tua, tokoh masyarakat, stakeholder terkait, pemerintahan, ataupun pihak swasta yang tergabung menjadi komunitas yang disebut komite sekolah memiliki kontribusi terhadap kesuksesan program pendidikan. Dengan demikian, tujuan pendidikan setiap sekolah dapat dicapai melalui kerjasama semua pihak yang terlibat dalam penyelenggaraan pendidikan. Artinya bahwa partisipasi komunitas (didalamnya para perwakilan orang tua siswa, masyarakat dan stakeholder terkait) yang diwadahi pada komite sekolah memberikan pengaruh yang cukup besar terhadap kesuksesan penyelenggaraan program pendidikan (Fatchurrohman, 2018). Oleh karena itu, pihak sekolah harus mampu membangun partisipasi komite sekolah lebih aktif yang bisa memberikan kontribusi terhadap peningkatan kualitas pendidikan. Hal ini disebabkan karena kualitas pendidikan yang dihasilkan tidak hanya terletak pada kompetensi guru, namun keterlibatan semua pihak termasuk orang tua juga sangan penting sebagai bagian dari komunitas tersebut (Qohar, 2018).

Hasil observasi dari tiga sekolah dasar di Mataram yaitu MIN KB, MI AI, SDIT SB pada studi pendahuluan ditemukan beberapa permasalahan pendekatan yang berkaitan dengan peningkatan partisipasi komite sekolah. Beberapa permasalahan yang telah teridentifikasi dari komunitas yang telah terbentuk, antara lain; 1) komite sekolah belum terlibat secara utuh dalam memantau kinerja kepala sekolah ataupun pembelajaran yang dilakukan guru di kelas melalui evaluasi laporan sekolah; 2) komite sekolah masih belum aktif memberikan masukan tentang layanan pendidikan sekolah; dan 3) komite sekolah belum berpartisipasi terhadap pembelajaran yang dibutuhkan di luar sekolah. Persoalan tersebut masih diperparah dengan pengelolaan pendidikan di sekolah yang belum efisien, demokratis, berkeadilan, dan partisipatif. Hal ini terjadi sebagai akibat adanya otonomi pengelolaan pendidikan dan profesional pada tingkat pemerintah daerah dan satuan pendidikan yang belum sepenuhnya terwujud. 
Vol. 12, No. 2 (2020)

Selanjutnya, partisipasi komite sekolah ini sangat bergantung pada cara dan kreativitas sekolah dalam menggunakan pendekatan yang relevan kepada semua pihak yang terlibat. Selain itu, tingkat partisipasi dan pendekatan yang dilakukan pihak sekolah dapat berdampak pada keikutsertaan anggota komunitas komite sekolah dalam setiap kegiatan sekolah. Keterkaitan partisipasi dalam sebuah organisasi dibutuhkan wadah yang baik. Salah satu yang sangat penting adalah wadah yang besar. Wadah ini dapat menampung segala kehendak positif masyarakat yang merupakan bagian penengah antara internal dan eksternal sekolah. Dengan demikian, posisi eksternal sangat urgen bagi keberlangsungan sebuah sistem pendidikan, hal demikian tidak bisa dianggap sebagai bayangbayang semata dalam tataran lembaga. Komite sekolah diposisikan eksternal feedback loops, yakni umpan balik eksternal yang muncul dari interaksi sekolah dengan lingkungan eksternal sekolah

Banyak penelitian yang telah mengkaji tentang pentingnya komite sekolah dalam proses penyelenggaraan pendidikan. Seperti pada penelitian dari Sharma tentang partisipasi komunitas dalam pendidikan dasar. Partisipasi masyarakat adalah komponen kunci dari kualitas penyelenggaraan program pendidikan berkelanjutan. Dengan demikian, School Management Committee di setiap sekolah memiliki mandat untuk memastikan transparansi dan kualitas serta melibatkan masyarakat (Varma, 2004). Di Kenya, Ngesu, Gakuru, Okuro, dan Kahingi mengamati bahwa masyarakat di daerah pedesaan memiliki sikap negatif terhadap pendidikan anak-anak mereka dan beranggapan bahwa pendidikan dasar kurang memiliki posisi penting dalam menentukan kehidupan anak-anak (Kilewo \& Frumence, 2015). Pandangan yang sama dari Chevedza, Wadesango, dan Kurebwa telah menemukan bahwa kemiskinan menimbulkan tantangan serius bagi upaya masyarakat pedesaan untuk menyediakan sumber daya pendukung pendidikan bagi anak-anak mereka di rumah dan sekolah (Chevedza, Wadesango, \& Kurebwa, 2012). Howley dan Maynard berpendapat bahwa orang tua tidak terlibat dalam pendidikan di luar pendidikan dasar biasanya gagal untuk melihat nilai pendidikan untuk anak-anak mereka dan mereka memiliki sikap resisten terhadap partisipasi dalam memberikan pendidikan (Maynard \& Howley, 1997). Jadi, masyarakat terlibat dalam menyediakan pendidikan dasar melalui persiapan anak-anak untuk sekolah dengan menyediakan makanan, seragam sekolah dan alat tulis (Godfrey, 2016). Sedangkan penelitian yang dilakukan Pandoyo \& Wuradji (2015) menyimpulkan bahwa kerja komite sekolah dasar negeri se-kecamatan Mlati sudah memiliki nilai yang cukup tinggi dalam berpartisipasi menjalankan program pendidikan di sekolah.

Proses penguatan sekolah dapat dilakukan melalui fungsi komunitas. Langkah-langkah yang memperkuat komite sekolah yang ada, hibah dan pelatihan, menunjukkan efek terbatas; sementara langkah-langkah yang 
Vol. 12, No. 2 (2020)

mendorong hubungan antara komite sekolah dan pihak lain, hubungan dan pemilihan, mengarah pada keterlibatan yang lebih besar oleh pemangku kepentingan pendidikan dan pada gilirannya untuk belajar (Pradhan et al., 2014). Nilai dari pengalaman pembelajaran berbasis komunitas ini adalah manfaat jangka panjang dari pengembangan kepemimpinan, rasa tanggung jawab sosial yang diperbarui, dan kesadaran komunitas yang direvitalisasi (Swift-Morgan, 2006). Partisipasi masyarakat cukup efektif dalam mencapai keberhasilan penyelenggaraan pendidikan (Swift-Morgan, 2006). Komite sekolah di Indonesia juga telah banyak memberikan kontribusi dalam penyelenggaraan pendidikan sehingga kualitas pendidikan menjadi lebih baik (Febriana, Isnaini, \& Syarifuddin, 2019; Suteng Sulasmono \& Murjini, 2017).

Dari paparan penelitian terdahulu diketahui bahwa hasil penelitian merujuk pada kajian partisipasi komunitas ataupun komite sekolah dan keterlibatan orang tua dalam penyelenggaraan pendidikan. Namun, dalam penelitian ini kegiatan kajian difokuskan pada konsep pendekatan partisipasi dari komite sekolah yang diperlukan untuk meningkatkan kualitas penyelenggaraan pendidikan di sekolah dasar Mataram. Hal yang menjadi alasan penelitian ini dilakukan adalah salah satu sumber yang perlu dikelola oleh madrasah-sekolah adalah lingkungan masyarakat atau orang tua murid, termasuk stakeholders. Organisasi madrasah-sekolah adalah organisasi yang menganut sistem tebuka, mau tidak mau, disadari atau tidak disadari selalu terjadi kontak hubungan dengan lingkungannya yang disebut sebagai suprasistem. Kontak hubungan ini dibutuhkan untuk menjaga agar sistem atau lembaga tidak mudah punah. Madrasah-sekolah dengan sistem terbuka yang memiliki megantropy, yaitu suatu usaha yang terus-menerus untuk menghalangi kemungkinan terjadinya entropy atau kepunahan. Hal ini berarti hidup matinya madrasah-sekolah akan sangat tergantung dan ditentukan oleh usahanya sendiri; dalam arti yang sederhana yakni menilik pada sejauhmana komite sekolah mampu menjaga dan memelihara komunikasi dengan masyarakat luas atau ornag tua sehingga penyelenggaraan pendidikan di sekolah dasar dapat berjalan sesuai dengan kebutuhan masyarakat dan tuntutan zaman.

Dengan demikian, tujuan dari penelitian ini adalah menemukan pendekatan partisipasi komunitas untuk meningkatkan kualitas pendidikan dan pengelolaan penyelenggaraan pendidikan sekolah dasar di Mataram. Hal ini berkaitan dengan madrasah-sekolah bukanlah lembaga yang berdiri sendiri dalam membina pertumbuhan dan perkembangan putra-putra bangsa, melainkan suatu bagian yang tidak terpisahkan dari masyarakat yang luas, dan bersama masyarakat membangun dan meningkatkan segala upaya untuk memajukan madrasahsekolah. 
Vol. 12, No. 2 (2020)

\section{METODE PENELITIAN}

Penelitian ini menggunakan pendekatan penelitian kualitatif deskriptif. Metode ini menyajikan secara langsung sifat hubungan antara peneliti dan responden. Penelitian kualitatif mengkaji tentang fenomena yang terjadi di lapangan sesuai dengan fakta-fakta yang terjadi (Creswell, 2012). Dalam konteks ini, peneliti sebagai pengamat yang terkait dengan pengamatan terhadap partisipasi komite sekolah, sehingga kemampuan interaksi, komunikasi, pemahaman, dan lingkungan yang diteliti sangat penting untuk mendapatkan data yang asli, akurat, objektif, dan benar.

Teknik pengumpulan data menggunakan observasi dan wawancara. Observasi dilakukan dengan melakukan pengamatan langsung ke sekolah untuk mengamati keterlibatan komite sekolah pada berbagai kegiatan yang diselenggarakan sekolah. Sedangkan wawancara dilakukan secara langsung oleh peneliti kepada partisipan. Partisipan dalam penelitian ini adalah kepala sekolah, guru dan perwakilan komite sekolah masing-masing sebanyak 3 orang dari Madrasah Ibtidaiyah Negeri (MIN) Karang Baru, Madrasah Ibtidaiyah (MI) AlIttihadul Islmiyah Ampenan, dan Sekolah Dasar Integrasi Terpadu (SDIT) Sekarbela. Teknik wawancara yang digunakan adalah wawancara tertutup karena peneliti telah menentukan pertanyaan yang akan ditanyakan kepada partisipan.

Teknik analisis data menggunakan tiga tahap yaitu reduksi data, penyajian data dan penarikan simpulan (Miles \& Huberman, 1994). Pertama reduksi data yaitu melakukan pengumpulan data yang diperoleh dari observasi dan wawancara dan dikategorikan. Kedua adalah penyajian data yaitu mengklasifikasi data sesuai dengan kebutuhan fokus masalah penelitian dan menganalisis data. Tahap ketiga adalah penarikan simpulan dari hasil analisis data yang telah dilakukan. Pemeriksaaan keabsahan data dalam penelitian ini dilakukan untuk memastikan kepercayaan data yang diperoleh menggunakan teori Lincoln dan Guba yang terdiri dari 4 langkah sebagai berikut, 1) kredibilitas, transferabilitas, ketergantungan, dan konfirmabilitas (Mayring, 2014).

\section{HASIL DAN PEMBAHASAN}

Pertanyaan yang diberikan dalam wawancara kepada kepala sekolah, guru dan perwakilan komite sekolah sebanyak 25 pertanyaan yang disajikan pada bentuk persentase dalam grafik sebagai berikut. 


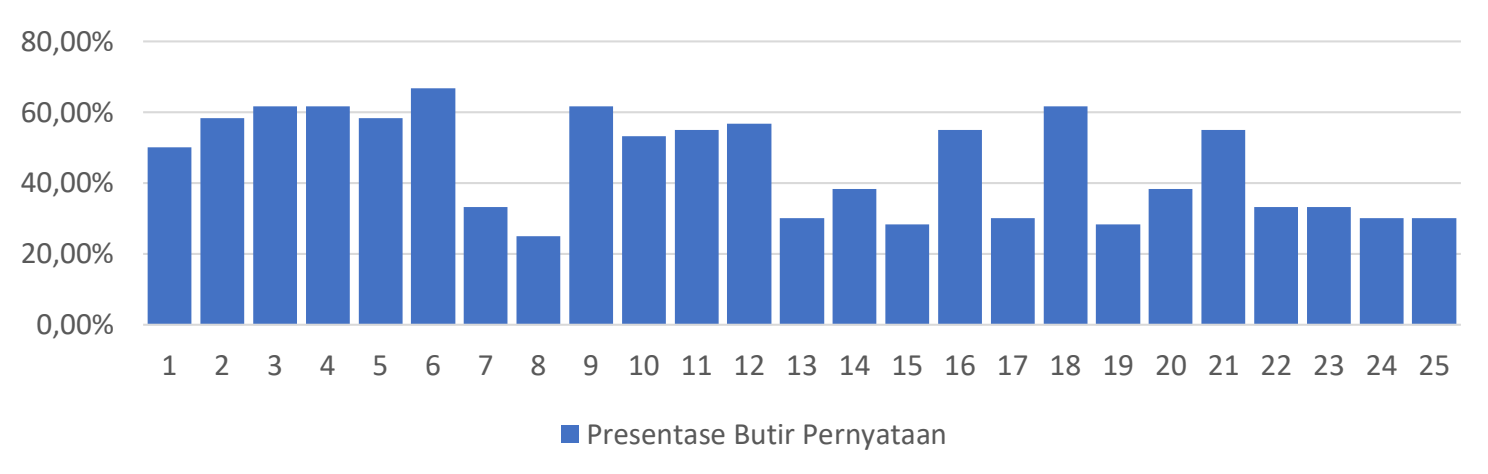

\section{Grafik 1 Hasil Analisis Data Wawancara Tentang Pendekatan Partisipasi Komite Sekolah}

Berdasarkan pada paparan data grafik di atas disimpulkan bahwa jenis pendekatan yang telah dimiliki oleh ketiga komite sekolah adalah sekolah sebagai pusat komunitas. Hal ini dapat dilihat dari persentase butir pernyataan nomor satu sampai 10 sebagai pernyataan yang berkaitan dengan pendekatan sekolah sebagai pusat komunitas. Pada butir pernyataan pertama diperoleh persentase sebesar $50 \%$. Artinya bahwa seluruh anggota komunitas komite sekolah bersama-sama dengan sekolah aktif menanamkan konsep kepada para siswa tentang pembelajaran sepanjang hayat, sehingga siswa dapat memiliki keterampilan hidup yang mampu membawa kepada proses menjalani kehidupan dengan baik. Butir pernyataan kedua memiliki persentase sebesar 58.3\%. artinya bahwa konsep pembelajaran di sekolah merupakan pembelajaran tambahan yang menyenangkan selain pembelajaran di lingkungan keluarga. Butir pernyataan ketiga sebesar $61.7 \%$, berarti bahwa anggota komunitas komite sekolah bersama orang tua dan sekolah aktif dalam memecahkan masalah proses pendidikan secara prosedur dan ilmiah. Butir pernyataan keempat memiliki persentase sebesar $61.7 \%$, artinya bahwa anggota komunitas komite sekolah aktif memanfaatkan teknologi untuk melakukan pendidikan seumur hidup. Hal ini diimplementasikan pada ide-ide penggunaan teknologi di kelas ataupun di rumah. Butir pernyataan kelima adalah $58.3 \%$, artinya bahwa anggota komunitas komite sekolah dan sekolah bersamasama mengarahkan, membimbing, dan mengembangkan kemampuan siswa secara individu. Kegiatan ini tidak dilakukan dengan generalisasi kemampuan setiap siswa.

Butir penyataan keenam memiliki persentase sebesar $66.7 \%$, artinya bahwa anggota komunitas komite sekolah dan sekolah memberikan pelayanan pendidikan terpadu dan komprehensif kepada siswa. Butir pernyataan ketujuh memiliki persentase sebesar $33.3 \%$, artianya bahwa anggota komunitas komite sekolah bersama-sama dengan sekolah melengkapi fasilitas sekolah dengan 
lengkap dan sesuai dengan kebutuhan. Butir pernyataan kedelapan memiliki persentase sebesar 25\%, artinya bahwa anggota komunitas komite sekolah bersama-sama dengan sekolah merancang kurikulum yang mampu bersaing dengan global dan kebutuhan lokal. Butir pernyataan kesembilan memiliki persentase sebesar $61.7 \%$, artinya anggota komunitas komite sekolah bersamasama dengan sekolah selalu melakukan komunikasi interaktif dua arah. Butir pernyataan kesepuluh memiliki persentase sebesar 53.3\%, artinya bahwa anggota komunitas komite sekolah bersama-sama dengan sekolah menetapkan tujuan pendidikan di sekolah secara komprehensif dan berdaya saing global.

Sekolah bukanlah tempat yang memiliki tempat inklusif yang tidak dapat disentuh oleh masyarakat ataupun proses pendidikan yang hanya berakhir setelah siswa menyelesaikan jenjang pendidikan pada tingkatannya. Namun, sekolah menjadi pusat pengembangan komunitas bagi masyarakat setempat dan menanamkan konsep bahwa pembelajaran dilakukan sepanjang hayat. Pendidikan seumur hidup didasarkan pada konsep bahwa seluruh individu harus memiliki kesempatan yang sistemik, terorganisir untuk "instruction", study dan "learning" di setiap kesempatan. Hal ini menunjukan bahwa pendidikan berlangsung tanpa batas yaitu mulai sejak lahir sampai kita meninggal dunia. Selain itu islam juga mengajarkan untuk mempelajari tidak hanya ayat qouliyah saja, tetapi ayat-ayat kauniyah, atau kejadian-kejadian di sekitar kita. Maka jelaslah sudah bahwa pendidikan seumur hidup itu sangat benar adanya didalam kehidupan kita. Dari penjabaran di atas, jelas bahwa pendidikan mempunyai peranan penting dan akan dinikmati oleh setiap orang sepanjang hayat mereka. Hal ini tentunya akan menjelaskan bahwa manusia perlu belajar. Pendekatan partisipasi komunitas melalui peran komite sekolah merupakan konsep cara yang digunakan oleh sekolah dalam mengembangkan penyelenggaraan pendidikan di sekolah dasar.

Pada temuan data disimpulkan bahwa sekolah telah menetapkan sebagai pusat partisipasi komunitas komite sekolah dalam melaksanakan proses pendidikan. Dari sekolah terbangun kolaborasi yang seimbang antara sekolah dengan komite sekolah. Implementasi pendekatan pengembangan partisipasi komunitas komite sekolah terwujud dalam kerja kolaborasi. Contoh kerja kolaboratif antara sekolah dan masyarakat menjadi cara yang digunakan untuk mensukseskan proyek konstruksi pembangunan sekolah dan perbaikan lingkungan.

Wawancara dengan kepala sekolah dan guru menunjukkan bahwa sekolah dan komite sekolah melakukan penggalangan dana secara bersama untuk membangun infrastruktur seperti lantai, pagar sekolah, memperbaiki lingkungan sekolah dan memperbaiki gedung sekolah. Dengan demikian, kebutuhan sarana dan prasarana pendidikan siswa dapat terpenuhi dan dirasakan nyaman. Dari contoh ini, pandangan terhadap komite sekolah yang hanya dianggap sebagai 
Vol. 12, No. 2 (2020)

tempat mengumpulkan sumbangan tidak benar. Namun komunitas melalui komite sekolah menjadi mitra sekolah dalam membangun sekolah.

Selain itu, sekolah dan masyarakat bekerja sama untuk mengumpulkan anak-anak agar mendaftar di sekolah. Hasil observasi ke sekolah ditemukan bahwa dinding masing-masing kantor sekolah memiliki foto kampanye pendidikan dengan partisipasi orang tua, masyarakat dan otoritas lokal, dan peta daerah untuk siswa yang diambil oleh guru dan masyarakat. Sekolah melakukan pertemuan dan membentuk jaringan desa untuk mengidentifikasi rumah tangga dan jumlah anak usia sekolah di masyarakat. Penelitian ini juga menemukan bahwa sekolah-sekolah memiliki jaringan dengan otoritas lokal untuk meningkatkan pendidikan, dan melindungi anak-anak dari kekerasan dan berbagai bentuk pelecehan lainnya. Sekolah-sekolah mengadakan pertemuan rutin untuk membangun konsep perlindungan anak usia sekolah dari pengaruh buruk kemajuan zaman dan teknologi. Karena perubahan peradaban tidak dapat dipungkiri akan mempengaruhi sikap dan perilaku siswa. Semua anggota komunitas komite sekolah dan stakeholder berbagi informasi dalam pertemuan.

Pendekatan pasrtisipasi dari komite sekolah dalam manajemen telah diterapkan pada semua aspek, kecuali penetapan keputusan yang menjadi tanggung jawab kepala sekolah atau wakilnya. Organisasi yang dibentuk ini dapat dikembangkan secara khas dan berakar dari budaya, demografis, ekologis, nilai kesepakatan, serta kepercayaan yang dibangun sesuai dengan potensi masyarakat setempat. Selain itu, sekolah perlu (1) memperkokoh pada kebijakan pusat atau pedoman melalui perumusan tujuan yang diambil berdasarkan pada faktor lokal dan fleksibilitas terhadap sekolah dan (2) rekomendasi kebijakan yang telah ditetapkan berdasarkan pada literatur terakhir dan pengalaman dari luar, tetapi masih belum memberikan perubahan di sekolah (Wong \& Evers, 2013).

Komite sekolah yang dibangun di manapun adanya harus merupakan pengembangan kekayaan filosofis masyarakat secara kolektif. Hal ini mangandung makna pengembangan konsep yang berorientasi pada pengguna (client model) dalam istilah ekonomi adalah pelanggan (customer) berbagai kewenangan (power sharing and advocacy model) dan kemitraan (partnership model) serta didukung oleh kemampuan dalam mengemban kepercayaan dari para orang tua terutama keberhasilan proses pendidikan (Newton \& Tarran, 2002)

Berdasarkan pada konsep komite sekolah, keberadaan komite sekolah di MIN Karang Baru, Madrasah Ibtidaiyah Al-Ittihadul Islamiyah Al Ijtihad Ampenan, dan Sekolah Dasar Islam Terpadu (SDIT) Anak Sholeh telah berorientasi pada kebutuhan pelanggan, dalam hal ini adalah orang tua dan siswa. Komite sekolah telah membangun berbagai kegiatan untuk siswa, orang tua dan guru. Jadi, ketiga pemeran dalam proses pendidikan tersebut memiliki persatuan yang kuat dengan tujuan yang sama yaitu membangun dan menghasilkan siswa 
Vol. 12, No. 2 (2020)

yang bukan hanya kaya dengan kuantitas, tetapi memiliki daya yang berkualitas baik akademik dan non-akademik sesuai dengan keinginan dan harapan dari harmoni sekolah dan masyarakat. Para orang tua telah dijadikan mitra oleh pihak sekolah dalam membangun kualitas pendidikan sehingga sekolah mampu memberikan pelayanan optimal. Kegiatan di MN Karang Baru, Madrasah Ibtidaiyah Al-Ittihadul Islamiyah Al Ijtihad Ampenan, dan Sekolah Dasar Islam Terpadu (SDIT) Anak Sholeh merupakan bukti pelayanan pendidikan kepada masyarakat.

Dalam menjalin relasi atau hubungan mesti saling menguntungkan antara madrasah-sekolah dengan masyarakat, yaitu dalam bentuk hubungan saling memberi, saling melengkapi, dan saling menerima sebagai patner yang memiliki kedudukan setara dalam kaitannya penyelenggaraan pendidikan. Dengan hubungan yang harmonis tersebut ada beberapa manfaat pelaksanaan hubungan sekolah dengan masyarakat (school public relation) (Newton \& Tarran, 2002). Selain hubungan harmonis tadi diperlukan kerjasama yang disesuaikan dengan wilayah dan arus globalisasi politik; adanya pembagian wilayah kebijakan politik sekolah, keuangan atau anggaran, kinerja, perluasaan dan perbaikan yang telah ditingkatkan, tetapi dibatasi pada wilayah kurikulum.

Komite sekolah memang dipandang sangat strategis sebagai wahana untuk meningkatkan mutu pendidikan di Indonesia, yaitu (1) mengatur arah, tujuan dan sasaran; (2) merencanakan bagaimana kemajuan yang akan dibuat atau pencapaian tujuan; (3) mengelola sumber daya yang dimiliki (sumber daya manusia, waktu, materi) sehingga tujuan secara ekonomis dapat dicapai sesuai dengan perencanaan; (4) pengendalian proses (yaitu mengukur pencapaian tujuan dan melakukan evaluasi dengan tepat); (5) mengatur dan meningkatkan standar organisasi. Sesuai dengan aspirasi berbagai kalangan masyarakat yang menyekolahkan anaknya di Madrasah dianggap mampu mengemban amanah mereka sehingga perlu diingat bahwa sekolah bukanlah suatu lembaga yang terpisah dari masyarakat.

Sekolah merupakan lembaga yang bekerja sama (teamwork-holistic) dalam konteks sosial. Sekolah memang lebih banyak dari masyarakat sekitar madrasah-sekolah sehingga keberadaannya bergantung pada dukungan sosial dan finansial masyarakat (the social and financial support of community) yang di lakukan dan diterapkan pada ketiga sekolah ini. Oleh karena itu, hubungan sekolah dan masyarakat merupakan salah satu komponen penting dalam keseluruhan kerangka penyelenggaraan pendidikan yang tersedia di tiga lembaga pendidikan ini. Dengan demikian, adanya hubungan yang harmonis antara sekolah dan masyarakat yang diwadahi dalam organisasi komite sekolah sudah tentu mampu mengoptimalkan model manajemen komite madrasah kaitannya dengan peran serta orang tua dan masyarakat dalam memajukan program 
Al-Ishlah: Jurnal Pendidikan - ISSN: 2087-949o (p); 2597-940X (e)

Vol. 12, No. 2 (2020)

pendidikan (the people participation of parent, sosial society, and education program). Pertama, orang tua dan masyarakat membantu menyediakan fasilitas pendidikan, memberikan bantuan dana serta pemikiran atau saran yang diperlukan sekolah. Kedua, orang tua memberikan informasi kepada sekolah tentang potensi yang dimiliki anaknya. Ketiga, tercipta harmonisasi manajemen antar-stakeholder serta mengupayakan peningkatan kinerja positif demi terlaksananya model manajemen peran komite madrasah yang berlandaskan semangat kerjasama, gotong royong dan pembangunan yang efektif, efisien, dan terjalinnya harmoni antar-stakeholder.

\section{SIMPULAN}

Pendekatan partisipasi komunitas komite sekolah dalam penyelenggaraan program pendidikan sekolah dasar di Kota Mataram adalah sekolah sebagai pusat komunitas. Artinya bahwa sekolah telah menanamkan konsep kerja sama dengan semua pihak yang perlu dilibatkan dalam membangun sekolah. Hal ini disebabkan karena pengembangan pendidikan tidak hanya dapat dilakukan oleh sekolah semata, tetapi melalui kerjasama kesuksesan pencapaian tujuan pendidikan dapat tercapai. Oleh karena itu, pendekatan partisipasi komunitas komite sekolah memiliki keselarasan yang harmonis dengan bentuk partisipasi yang telah dikembangkan di sekolah.

Konsep pendekatan tersebut memberikan pemahaman bahwa komunitas yang terdiri dari berbagai kelompok individu harus mampu pula mengajarkan pemahaman kepada siswa tentang pembelajaran seumur hidup. Dengan demikian, sekolah dan komunitas dapat menerapkan konsep partisipasi yang selalu merujuk pada refleksi diri dan selalu belajar bersama dalam menyelesaikan masalah ataupun melakukan perbaikan peningkatan pengelolaan sistem pendidikan.

\section{DAFTAR PUSTAKA}

Chevedza, E., Wadesango, N., \& Kurebwa, M. (2012). Factors That Militate Against the Provision of Quality Education at Grade Seven Level in Gokwe South Central Cluster of Zimbabwe. International Journal of Educational Sciences, 4(3), 223-229. https://doi.org/10.1080/09751122.2012.11890046

Creswell, J. W. (2012). Educational Research: Planning, Conducting, and Evaluating Quantitative and Qualitative Research. London \& New York: Pearson Education.

Fatchurrohman, F. (2018). Kemitraan Antara Sekolah, Orang Tua, Dan LembagaLembaga Sosial Kemasyarakatan Di Madrasah Aliyah Negeri Salatiga. Akademika: Jurnal Pemikiran Islam, 23(1), 129. https://doi.org/10.32332/akademika.v23i1.1207

Febriana, L., Isnaini, M., \& Syarifuddin, A. (2019). Peranan Komite Sekolah Dalam Meningkatkan Mutu Pendidikan Di MAN 1 Palembang. Jurnal PAI 
Al-Ishlah: Jurnal Pendidikan - ISSN: 2087-949o (p); 2597-940X (e)

Vol. 12, No. 2 (2020)

Raden Fatah (Vol. 1). https://doi.org/10.19109/PAIRF.V1I2.3234

Godfrey, S. M. (2016). Challenges Impacting Community Participation and Their

Effect on Teaching and Learning: a Case Study of Rural Areas. European

$\begin{array}{llll}\text { Scientific Journal, } & \text { ESJ, }\end{array}$ https://doi.org/10.19044/esj.2016.v12n25p345

Kilewo, E. G., \& Frumence, G. (2015). Factors that hinder community participation in developing and implementing comprehensive council health plans in Manyoni District, Tanzania. Global Health Action, 8(1). https://doi.org/10.3402/gha.v8.26461

Maynard, S., \& Howley, A. (1997). Parent and Community Involvement in Rural Schools. ERIC/CRESS, P.O. Box 1348, Charleston, WV 25325 (free). Retrieved from www.eric.ed.gov

Miles, M. B., \& Huberman, A. M. (1994). Qualitative Data Analysis; An Expanded Sourcebook. New Delhi: Sage Publication.

Newton, C., \& Tarran, T. (2002). Managing Change In Schools A Practical Handbook. London \& New York: Routledge.

Pandoyo, R., \& Wuradji, W. (2015). Pengaruh Kepemimpinan Kepala Sekolah, Kinerja Guru, Komite Sekolah Terhadap Keefektifan SDN Se-Kecamatan Mlati. Jurnal Akuntabilitas Manajemen Pendidikan, 3(2), 250-263. https://doi.org/10.21831/amp.v3i2.6341

Pradhan, M., Suryadarma, D., Beatty, A., Wong, M., Gaduh, A., Alisjahbana, A., \& Artha, R. P. (2014). Improving educational quality through enhancing community participation: Results from a randomized field experiment in Indonesia. American Economic Journal: Applied Economics, 6(2), 105-126. https://doi.org/10.1257/app.6.2.105

Qohar, H. A. (2018). Manajemen Komite Sekolah Sebagai Badan Pendukung (Supporting Agency) Dalam Upaya Meningkatkan Mutu Pendidikan Di SLB Kabupaten Garut Dan Kabupaten Sumedang. Inclusive: Journal of Special Education, IV(1).

Suteng Sulasmono, B., \& Murjini, M. (2017). Evaluasi Kinerja Komite Sekolah Dalam Peningkatan Mutu Pendidikan. Jurnal Cakrawala Pendidikan, 36(1). https://doi.org/10.21831/cp.v36i1.10431

Swift-Morgan, J. (2006). What Community Participation in Schooling Means: Insights from Southern Ethiopia. Harvard Educational Review, 7(3).

Varma, V. S. (2004). Community Participation and Empowerment in Primary Education. Contemporary Education Dialogue, 1(2), 292-296. https://doi.org/10.1177/097318490400100211

Wong, K., \& Evers, C. W. (2013). Leadership for Quality Schooling International Persfective. London: Routledge. 